\title{
An empirical investigation of the effect of employees' customer orientation on customer loyalty through the mediating role of customer satisfaction and service quality
}

\author{
A. Aburayya ${ }^{a^{*}}$, A. Al Marzouqi ${ }^{\text {b }}$ D. Alawadhic ${ }^{\text {F. }}$. Abdoulid ${ }^{\text {and M. Taryam }}{ }^{e}$ \\ ${ }^{a}$ Quality and Excellence Officer, Quality \& Corporate Development Office, Dubai Health Authority, Dubai, UAE \\ ${ }^{b}$ Assistant Professor, Acting Dean, College of Health Sciences, University of Sharjah, Sharjah, UAE \\ ${ }^{c}$ Consultant, Head of Quality \& Corporate Development Office, Primary Health Care Sector, Dubai Health Authority, Dubai, UAE \\ ${ }^{d}$ Consultant, Head of Center, Health Centers Department, Dubai Health Authority, Dubai, UAE \\ ${ }^{e}$ Consultant, Chief Executive Officer, Primary Health Care Sector, Dubai Health Authority, Dubai, UAE

\section{H R O N I C L E}

\section{A B S T R A C T}

\section{Article history:}

Received: February 15, 2020

Received in revised format:

March 162020

Accepted: March 16, 2020

Available online:

March 16, 2020

Keywords:

Customer Orientation

Customer Satisfaction

Perceived Service Quality

Customer Focus and Feedback

SERVQUAL

Customer loyalty

Structural Equation Modelling

Dubai Primary Healthcare Ser-

vices
The primary objective of the current study was to establish and authenticate a conceptual framework that combines the correlation between customer orientation, service quality, customer satisfaction, and customer loyalty. Data were gathered from primary healthcare centres in the United Arab Emirates (UAE), particularly in Dubai. A questionnaire as the main quantitative tool was adopted to collect data through a self-administered method using the drop-off technique. Frontline healthcare professionals filled questionnaires examining customer orientation while patients filled questionnaires assessing three variables; customer satisfaction, loyalty, and perceived service quality. Questionnaires from patients were then paired with those from healthcare providers attending to the patients. In total, 205 employee surveys and 3,070 customer questionnaires were used in the study, yielding $80.1 \%$ and $70.3 \%$ response rate, respectively. In this study, hypotheses were tested using a Structural Equation Modelling (SEM) method with LISREL 9.30. The suggested model shows that customer satisfaction completely mediated the impact of employees' customer orientation on their loyalty. Besides, customer orientation was indicated to be positively correlated to the quality of service and customer satisfaction, and that consumer satisfaction has a more considerable impact on consumers' decision to be loyal than service quality.

C 2020 by the authors; licensee Growing Science, Canada

\section{Introduction}

The healthcare sector has become a key driver of globalisation. Given its broad coverage and importance, the public healthcare sectors in most countries worldwide are overseen by the national governments and supplemented by private healthcare services. Concurrently, UAE Ministry of Economy (2019) in its recent report, underlined that healthcare is among the global economy's vast growing sectors, with a total worldwide expenditure of $\$ 7,682$ trillion in 2015. In a similar report, the Economist Intelligence Unit (EIU) (2016) estimated that expenditure on health increased rapidly in most countries by more than $5.2 \%$ annually between 2014 and 2018, amounting to more than $\$ 9.30$ trillion. In their recent report, Aburayya et al. (2019b) noted that UAE has gradually shifted towards excellence in the public sectors, including healthcare, to modernise the existing traditional administration structures in most public sectors. According to Aburayya et al. (2019b), the country's visions 2021 underscores the essence of improving the capacity of the country's healthcare providers and expand the sector's infrastructure to meet the rapidly growing public health needs and demands. Besides, a joint report by U.S.-U.A.E. Business Council (2018) indicated that UAE investments in the healthcare sector over the last decades have made the country experience a fundamental transformation in service delivery to the public. For instance, the number of public and private hospitals in the U.A.E. has increased significantly from seven to 120 . The proportion of health centres has also grown from 12 to 150 . Moreover, 
Aburayya et al. (2019a) noted that recently the country focus has been on enlarging its healthcare infrastructure to meet international standards.

In the recent past, government expenditure on health care has increased substantially. For instance, the UAE government spent $\$ 1.3$ billion in health in 2018 , double the amount spent on the sector less than a decade ago, as reported by the U.S.-U.A.E. Business Council (2018). The U.S.-U.A.E. Business Council (2018) attributes such an increase in expenditure partly to the population growth. UAE prioritises health in its development agenda in line with the World Health Organisation's emphasis that primary health care (PHC) is the core foundation of the healthcare system. The global report released in 2008 named "Now more than ever" underlined the need to enhance the quality of primary care services to satisfy consumer demand. Half a decade later, in 2013, the global report was directed to "Universal Health Coverage." Nevertheless, further discussion on patients' request, quality of service as well as the restructuring of the health systems are crucial since still there are different kinds types of healthcare delivery discrepancies and configurations worldwide (Al Bolushi et al., 2017). Markedly, healthcare consumers are indispensable material and intellectual capital of the firms. In this respect, the success of any institution entirely depends on consumer attitude and fast service to the customers, as underlined by Raie et al. (2014). Therefore, an in-depth understanding of consumer needs and the development of a plan to meet them are essential for organisations. Indeed, growing interests in customer orientation, the rapid advance in technology, increasing competition, and globalisation have modified the customer; hence old ideas cannot be sufficiently employed or even survive in the current world (Jarideh, 2016). Many researchers including Brockman et al. (2012), Zablah et al. (2012), Gazzoli et al. (2013), Raie et al. (2014), and Jarideh (2016) emphasised the role staff to customer or frontline workers in ensuring the success of any institution. Positive results of an organisation, such as customer loyalty and satisfaction, can result from the interaction between service providers and consumers (Jarideh, 2016). According to Jarideh (2016), customers judge service quality based on the behaviour of the service provider. In this regard, employee-customer orientation is a vital determiner of the success of any organisation (Gazzoli et al., 2013). Moreover, consumer orientation is an essential element of the concept of marketing (Zablah et al., 2012; Gazzoli et al., 2013). Hence its execution in a firm is performed through customer-oriented workers and their interactions with the customers (Brockman et al., 2012; Gazzoli et al., 2013; Raie et al., 2014). Furthermore, the increasing competitiveness in the service economy together with the recent global crises, delivery of high-quality customer services and orientation with the customers become increasingly important than ever (Farrell \& Oczkowski, 2012). Given that healthcare services are intangible and interactive, customers' assessment of the quality of service is best based on employee behaviour and attitudes as argued by Teng and Barrows (2009) and Gazzoli et al. (2013). As a result, the level of employee orientation on customers plays a valuable role in the firm's performance outcomes and eventual success (Farrell \& Oczkowski, 2012; Raie et al., 2014; Jarideh, 2016). In other words, given that since workers play a vital role in the delivery of service delivery, the ones with considerably high customer orientation levels develop more constructive interactions with consumers. In turn, such communications influences how customers view the quality of service delivered and their overall contentment with such services. Abundant studies have shown that customer contentment, their perception of service quality, as well as their customers' judgment whether to stay loyal or change service providers, are considerably determined by the contact employee customer-oriented attitudes as well as their behaviours employees (Gazzoli et al., 2013; Raie et al., 2014; Jarideh, 2016).

Nonetheless, current research shows that there are limited empirical studies to affirm the correlation among these constructs, especially in the Middle East. To the best of the authors' knowledge, no studies have focused on the correlation among such constructs in the area of primary public healthcare services in UAE. In this respect, the main objective of this study is to establish and validate a conceptual model that integrates the correlations among customer orientation, service quality, customer satisfaction, and customer loyalty in the context of primary healthcare services in Dubai. The study further tends to recommend a different study design to examine the associations suggested in the current research model. Notably, most of the existing studies assessing how customer orientation influences their experience employed the same population sample. That is, they used only employee or customer responses (Zablah et al., 2012; Raie et al., 2014). Consequently, the methodological input of the current study provides further insights into the possible correlation between customer orientation and their experiences thereby, reducing common method bias evident in previous studies on this topic.

\section{Literature Review}

\subsection{Employees' Customer Orientation}

Gazzoli et al. (2013) noted that the customer orientation concept was established first by Levitt (1960). Given that the idea is a fundamental element of marketing practice and theory, as noted by Farrell and Oczkowski (2012), Zablah et al. (2012), Gazzoli et al. (2013), and Raie et al. (2014), research has increasingly focused on it over the last several years resulting to different definitions in different studies. Jarideh (2016) asserts that customer orientation alludes to customer knowledge and the ability to create superior value regularly s to themselves. In another study, Lee et al. (2011) define customer orientation as the contact staff's willingness to assist customers to examine their needs, help them make appropriate order decisions, offer services that meet customer needs and avoid using high-pressure sales approaches. Lee et al. (2013) further defined customer orientation as the employee's inclination or tendency to meet consumer needs as part of their job responsibilities. Customer orientation is also defined as the firm's ability and willingness to identify, assess, comprehend, and respond to consumer needs (Yazdani et al., 2011). 
Brown et al. (2002) suggested two basic customer orientation dimensions, including needs and enjoyment. According to Brown et al. (2002), the aspect of needs is associated with the worker's beliefs in their capability to address consumer needs. However, the dimension of enjoyment is related to that workers can get pleasure from interacting and serving the customers' needs. Views based on these two dimensions suggest that employee consumer orientation is not simply linked to satisfying customer needs but also employees' pleasure to address or serve the customers (Lee et al., 2011). In other words, customer orientation is related to the level of contact employees conduct in their interaction with consumers, to address customer needs and also serve them with pleasure. Hennig-Thurau (2004) further identified four distinct dimensions under the concept of customer orientation, including motivation, social skills, technical skills, and decision-making authority. Employee technical skills allude to the knowledge and technical skills that an employee requires to offer service to address customer needs in the interactive process. On the other hand, social skills refer to employee ability to understand and consider customers' views during interactions. Such an approach can be attained visually, emotionally, and cognitively (Raie et al., 2014). They underlined that the three aspects help employees to identify consumer needs and hence they are crucial to meet customer needs (Raie et al., 2014). Concurrently, Lee et al. (2013) assert that motivating workers to serve customers entails three elements including positive attraction-oriented conduct, perceptions of their capacity to conduct themselves in a client-oriented manner, and employee expectations to realise intended outcomes by participating in such behaviour. Besides, Raie et al. (2014) remarked, motivation is essential to turn technical and social skills to consumer-oriented conduct. Nevertheless, decision-making authority refers to the degree to which employees or service providers have the power to make decisions regarding issues associated with customer needs and interests thus such power is also related to the notion of empowerment (Hennig-Thurau, 2004). Apart from motivation, employee decision-making authority is essential for the transfer of social and technical skills; hence employees play a crucial role in customer-oriented (Hennig-Thurau, 2004).

\subsection{Customer Satisfaction, Service Quality, and Customer Loyalty}

Liang and Zhang (2012) define customer satisfaction as the consumer good feel, which results from his/her view of proper product or service performance in line with his/her expectations. Precisely, satisfaction is a positive sensation created in an individual after using a certain product. Therefore, feelings of satisfaction develop if the products customers receive meet their expectations. However, as noted by Abdolahian and Foroozandeh (2011) in their study that adopted Oliver's (1981) concept of customer satisfaction, if the quality of products below customer's expectations, they lead to dissatisfaction. Oliver (1981) defined customer satisfaction as a psychological state that results when emotions around confirmed or disconfirmed consumer expectations are combined with the consumer's previous feelings regarding the consumption experience. In this context, the term disconfirmation is related to the fulfilment of consumer expectations and can be positive where the product performance exceeds consumer expectations, negative where product performance is below consumer expectations, or zero where performance is the same as expectations. Precisely, consumer expectations are confirmed when a good or service performs to the expectation, negatively disconfirmed when the good or service performs below the expectation, and positively disconfirmed when the services or goods perform better than expected (Kim, 2011). Such a paradigm is known as confirmation/disconfirmation and results in an emotional reaction known as satisfaction or dissatisfaction (Kim, 2011). Moreover, researchers are increasingly interested in quality as a crucial aspect of most customer service industries, including hospitals. In their recent study on this topic, Aburayya et al. (2019a) assert that establishing reputable quality services consumers helps firms in the service industry to gain competitiveness and maintain long-term profitability. In a similar study, Alghamdi (2018) underlined that emphasis on quality among companies in the service sector is important for helping to enhance business performance. Concurrently, Aburayya et al. (2019a) assert that consumers demand quality; thus, organisations have to adopt quality systems that help to meet customer expectations. Parasuraman et al. (1988) emphasised on customer's voice, and defined service quality as the difference between consumer expectations of service and the views of the actual service received. This concept led to the development of the SERVQUAL instrument. Initially, SERVQUAL was introduced as a generic measure of any assistance. Nevertheless, Carman et al. (1996) study showed the need to customize SERVQUAL to deliver a particular service. Besides, Parasuraman et al. (1988) acknowledged that the introduction of SERVQUAL offered a tool for examining the quality of service applicable in a wide range of services. The SERVQUAL dimensions have been widely used in the healthcare literature. In their exploratory study on different healthcare service quality dimensions, Fatima et al. (2018) screened 1921 surveys and confidently concluded that SERVQUAL dimensions are among the top utilised dimensions in the assessment of healthcare service quality but with inadequate use of some of the models' dimensions. They also noted that SERVQUAL dimensions are among the commonly used dimensions in examining the quality of healthcare services in most developing countries. Parasuraman et al. (1988) identified various aspects, including tangibility, reliability, assurance, responsiveness, and empathy as a key for service quality. Fatima et al. (2018) clarified that tangibles dimensions include physical equipment, facilities, and personnel appearance. On the other hand, reliability refers to employee capability to undertake the required service accurately and dependably while responsiveness is willingness to assist consumers and offer prompt service. Assurance entails employee courtesy and knowledge and their ability to inspire confidence and trust. At the same time, empathy alludes to individualised and caring attention an organisation offers to the customers upon understanding their specific needs (Pathirana, 2019).

Kim (2011) defined customer loyalty as the feeling of affection or attachment to the firm's employees or products. Marketing researchers have supported the use of behavioural scales to examine customer loyalty as including the share of purchase which reflects the level of customer loyalty. From a different perspective, Jarideh (2016) argued that although customer loyalty, as 
well as their repeat purchase behaviours, are closely related, most researchers prefer the use of behavioural scales as an effective loyalty assessment tool. For instance, various circumstantial constraints, such as product accessibility influence customer behavioural loyalty (Aghamolaei et al., 2014). Consensually, Kim (2011) asserts that in this situation, behavioural scales might fail to differentiate false loyalty from a genuine one. As an alternative, Dean (2007) suggests the use of attitudinal scales focusing on the consumer-level of emotional or trust attachment. Kim (2011) supported Deans' (2007) view arguing that both attitudinal and behavioural measures are essential to appreciate the full image of consumer loyalty since the two dimensions of loyalty are integral. In this regard, the current study employed the concept of customer loyalty with both attitudinal and behavioural aspects.

\subsection{Relationships between Customer Orientation, Service Quality, Customer Satisfaction, and Customer Loyalty}

The correlation between customer orientation, customer satisfaction, customer loyalty, and service quality has been widely explored in research resulting in diverse views. Kim (2011), Lee et al. (2013), Raie et al. (2014), Jarideh (2016) consensually assert that customer satisfaction customer orientation, and service quality is essential forces in establishing customer loyalty. Mohammad et al. (2013) argue that firms oriented toward customer know everything regarding their clients both individually and in groups. Such organisations not only make decisions suitable for quality customer services but also create strategic structures and properly manage client information to improve the quality of services. Additionally, such firms ensure coordinated flow and handling of customer information among subdivisions and establish well-thought-out decision-making measures that are in customers' interests. Concurrently, Ruud et al. (2016) assert that organisations that want to enjoy the benefits of improved relations with the customers should consider customer orientation as a key strategic option because being oriented to customer needs regarding quality means making the customers the company's pivot of its marketing programs. In similar studies, Ruud et al. (2016), Dadia and Idenedo (2017), and Mohammad et al. (2013) noted that customer orientation is a key market orientation dimension rewarded customer loyalty coupled with superior performance. Concurrently, Gazzoli et al. (2013) assert that service quality is an essential component in decision-making and the worker and customer interaction becomes an important aspect in determining customer's perceptions of service quality. In the same line, Gazzoli et al. (2013) added that employee's attitude or their willingness to serve, conduct or their helpfulness, and expertise or their knowledge in service delivery are three essential elements that determine customer view quality of service. In further studies, Kim (2011), Gazzoli et al. (2013), and Jarideh (2016) agree that personal interactions between employees and customers have a significant influence on customer perceptions of service quality. Unfriendly employees are a clear indicated of poor quality and possible lack of customer orientation hence unknowledgeable on customer quality needs. Blocker et al. (2011) held a similar view underlining that customer orientation predicts service quality and empirically showed that customer orientation mediates the relationship between customer satisfaction and employee personality. They concluded that service quality in a company depends wholly on employees' ability to offer excellent services to all customers (Blocker et al., 2011). Raie et al. (2014) and Jarideh (2016) consensually noted that if customers have a positive view of the quality of interaction with employees in the service delivery, they portray high levels of satisfaction. Similar sentiments were presented by Lee et al. (2011), Lee et al. (2013), Liang and Zhang (2012) that particular contact employees' behaviours directly determine customer satisfaction. In this respect, the following hypotheses were proposed:

H1: Customer orientation for the frontline employee has a positive and significant effect on the customer loyalty.

H2: Customer orientation for the frontline employee has a positive and significant effect on the customer's perception of service quality.

H3: Customer orientation for the frontline employee has a positive and significant effect on customer satisfaction.

Abundant studies have been conducted concerning an association between contact employee customer orientation and these three elements (Kim, 2011; Rai \& Medha, 2013; Waari, 2018). Kim (2011) argued that customer satisfaction has more influence influences on customer loyalty than employee customer orientation, implying that both factors influence one another. In response to Kim's (2011) sentiments, Kheng et al. (2010) underlined that customer orientation determines employee understanding of customer needs and positive customer relations with the employees. In turn, such knowledge and relations assess customer satisfaction and loyalty. From a different perspective, Kheng et al. (2010) pointed out that the quality of service influences corporate outcomes, such as improving customer relations and stimulates customer loyalty. Essentially, excellence in service quality is fundamental to attain customer loyalty, the prime goal of all organizations. Currently, customers are increasingly aware of their rights; hence organisations require constant progress in service quality to sustain the changing demands and growing competition and gain customer loyalty (Kheng et al., 2010). Rai and Medha (2013) held a similar view elaborating that customer loyalty results from sustained customer satisfaction, emotional attachment, service provider willingness and consistency in the preference, patronage, and premium. In other words, satisfied clients often buy from satisfying organizations. However, Chen et al. (2016) hold different views that customer satisfaction is related to the customer's comparison of their pre-purchase perceptions and the actual service experienced. Chen et al. (2016) also note that customers' satisfaction is an indicator of a firm that is establishing customer loyalty towards a product. The positive correlation between customer loyalty and their satisfaction and loyalty was further supported by Mohsan et al. (2011), Chiguvi and Guruwo (2017), 
and Waari (2018). Accordingly, the association between quality of service, customer satisfaction and loyalty were hypothesised as follows:

H4: Perceived service quality has a positive and significant effect on customer loyalty.

H5: Customer satisfaction has a positive and significant effect on customer loyalty.

After the proposed paths, H1 through H5 were combined, two mediating correlations were apparent. Fig. 1 shows a complete model with hypothesised correlations. That is, quality of service as a mediator between customer loyalty and customer orientation (Customer Orientation $\rightarrow$ Service Quality $\rightarrow$ Customer Loyalty), the satisfaction of the customer as a mediator between customer orientation and Loyalty; Customer Orientation $\rightarrow$ Customer Satisfaction $\rightarrow$ Customer Loyalty. In this regard, the following hypotheses were proposed:

H6: Service quality mediates the effect of frontline employees' service orientation on customer loyalty.

H7: Customer satisfaction mediates the effect of frontline employees' service orientation on customer loyalty.

\section{Methodology}

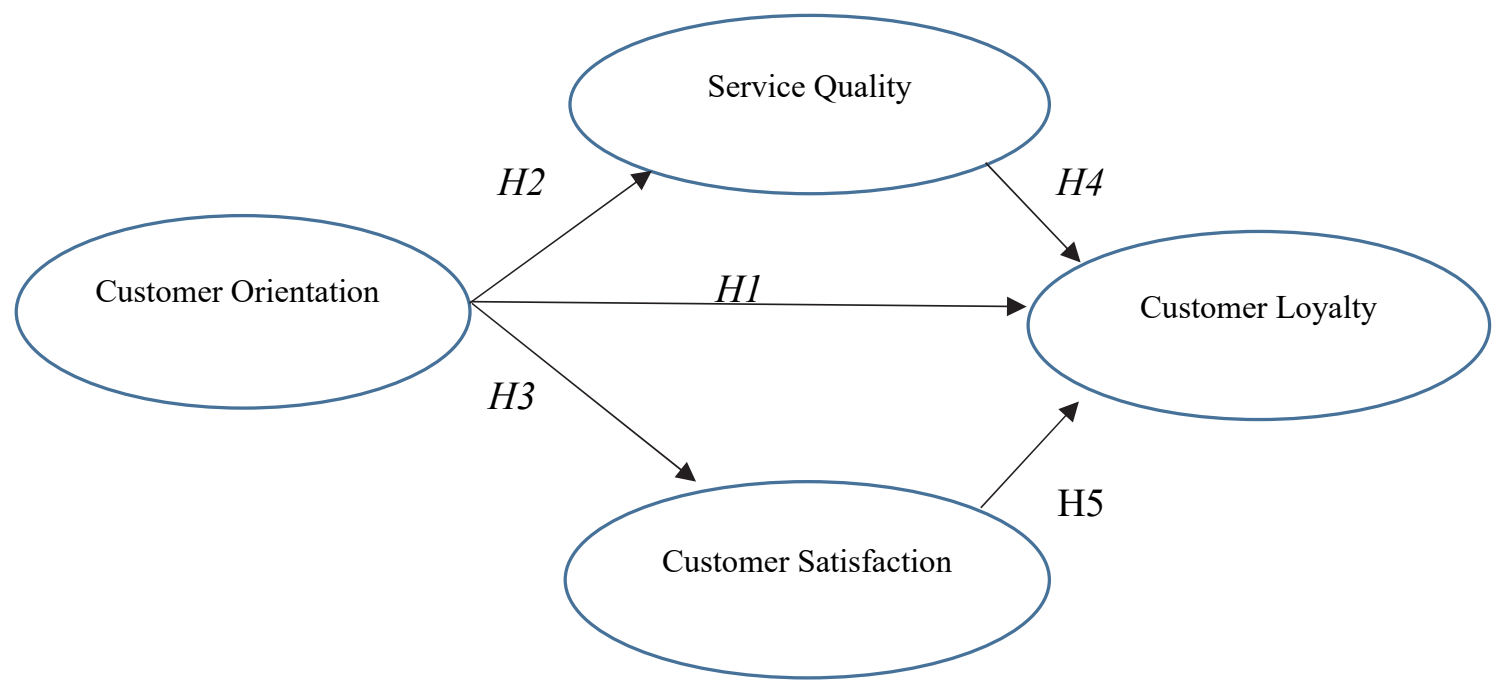

Fig. 1. Research framework

The study deployed a quantitative approach based on a survey study design to attain its objectives. A questionnaire was used as the prime quantitative tool to gather data. The researcher personally administered the questionnaires and picked them later for analysis, also known as the drop-off technique. This survey was carried out at primary healthcare clinics in Dubai, UAE engaging 12 healthcare clinics between 2 and 29 January 2020. Therefore, it took for four weeks to gather the required data from happiness centres' frontline or contact workers, including registration staff and clerks who were in face-to-face contact with patients. All patients who visited the clinics during the study period were involved in the survey except the ones who had emergency medical situations, mental illness or aged below 18. Two research tools were designed due to the conceptual combination of frontline workers and patients' views presented in the study. The first questionnaire examined the level of employee-customer orientation based on contact employees' perceptions. At the same time, the second instrument assessed the quality of service, satisfaction of customers, and customer loyalty based on perceptions of patients. The researcher met with centres' managers to explain the scope and purpose of the survey and data gathering procedures. Several survey packages containing one employee survey and 20 customer surveys were distributed to each clinic. The instruments were designed based on centres' patient census for each month. Notably, only service-contact workers were involved in the research. Once the surveys were complete, the management was requested to dispense the customer surveys to the patients. Employee surveys were coded numerically, and one specific number was assigned to each frontline employee. Patient questionnaires were coded with a similar amount given to the particular employee. Such a procedure enabled the researcher to track customer responses regarding the kind of service quality delivered by a specific worker. Mainly, the current study required a large sample to minimise sample error associated with the non-probability sampling approach and enhance the precision of the sampling outcome as well as its generalisability. A total of 205 frontline employee surveys and 3,070 customer or patient questionnaires were deployed, yielding $80.10 \%$ and $70.30 \%$ response rates, respectively. From Morgan's (1979) understanding, a sample size of 205 workers and 3,070 customers is superior to the proposed requirements. Therefore, it was appropriate to employ SEM for hypotheses testing. Markedly, the hypotheses were formulated based on the existing theories and tested using a SEM approach with LISREL 9.30. Cronbach's alpha combined with factor analysis was used to examine the measurement model to comprehend whether or not the instruments were valid and reliable. The SPSS 25 program was deployed in this assessment. 
In the current study, customers examined service quality received from service-worker and their level of loyalty and satisfaction with the services offered. The patient's responses were combined and matched to the encounter analysis level. This process is based on the idea that data should be gathered at a level at which it will be analysed. In total, the aggregation represents 14 customers or patients to one contact employee. In order to empirically test the theoretical model hypothesized in this study, it was first necessary to operationalize these theoretical constructs so that empirical investigation was possible. Therefore, a set of items for measuring the constructs of customer orientation, service quality, customer satisfaction and customer loyalty had to be adequately developed. Remarkably, care is needed in choosing or developing to tap the conceptual domain of each of the theoretical constructs comprehensively. In this respect, a 12-item customer orientation scale designed by Hennig-Thurau (2004) was used in this study to explore customer orientation. The scale consisted of four dimensions, including social skills, motivation, technical skills, and decision-making authority. The constructs were measured based on a 5-point Likert scale ranging from 1, representing "strongly disagree", to 5 representing "strongly agree". The SERVQUAL model designed by Parasuraman et al. (1988) was employed to measure the quality of service the patients involved in the study. The model comprises 13 items consisting of five service quality dimensions, namely, tangibles, responsiveness, assurance, empathy, and reliability. The construct was gauged on a 5-point Likert-type scale that ranged from 1, implying "strongly disagree", to 5, implying "strongly agree". Regarding customer satisfaction construct, customers were requested to show their satisfaction level at the clinics based on the statement "Overall, how satisfied are you with services provided by this clinic?" This oneitem scale assessing the level of global satisfaction was adapted from the study by Scotti et al. (2007). A 5-point Likert scale that ranged from very dissatisfied to very satisfied was employed to record patient responses. However, patients' loyalty was measured based on four items. The first two items regarded behavioural loyalty, while the other two related to customer attitudinal loyalty (Baloglu, 2002). All the issues were examined on a 5-point Likert scale ranging from 1 for "strongly disagree" to 5 for "strongly agree".

\section{Data Analysis}

\subsection{Participants Description}

In total, 3,070 customers or patients have involved in this study, where 58.60 per cent of them were female while the rest 41.40 per cent were male. Participants demography indicated that more than 61.80 per cent of patients were aged below 59 years. Regarding nationality, the sample consisted of 66.70 per cent Emirati and 33.30 per cent non-Emirati. The higher proportion of Emirati participants was attributed to the fact that the study was conducted in the public sector, where a high proportion of Emirati patients have health insurance; hence they receive treatment for free. Regarding patients' distribution by type of visit, the outcome illustrates that most of the patients $(58.60 \%)$ consisted of follow-up patients, while 41.40 per cent of them visited walk-in clinics. On the other hand, employees sample consisted of 205 participants, with 71.70 per cent of them being women. The high proportion of female participants was because most of the workers in the primary healthcare sector in the country were females. About 73.10 per cent of the participants were aged between 31 and 40 and 41 to 50 years. Regarding education level, $67.8 \%$ of the participants had bachelor degrees, and about 15.90 per cent had postgraduate degrees. Further results were that close to 69.90 per cent of the participants had been employees in the clinics for over 5 years, but only 10.60 per cent of them had supervisory skills.

\subsection{Measurement Model Analysis}

The researcher employed two instruments in this study to collect primary data from clinics to test the hypothesised theoretical model. The reliability and validity of the instrument were evaluated before testing the theoretical model. Notably, hypothesis testing was carried out based on valid and reliable measurement scales. Precisely, reliability and factor loading analyses were done to measure the data validity and reliability of the chosen constructs in the current study. Cronbach's alpha coefficient was employed to examine the internal consistency reliability while construct validity was examined using factor loading analysis. The findings of the factor analysis and internal consistency reliability tests are illustrated in Table 1. Primarily, all the constructs were gauged using the measurement model analysis apart from the customer satisfaction scale because it is a single-item scale. Markedly, participants were required to show their satisfaction level with the statement "Overall, how satisfied are you with services offered by this clinic?" The one-item scale assessing global satisfaction was developed by Scotti et al. (2007). Despite that a multiple-item measure is desirable, the literature recommended the use of single-item global satisfaction measures (Scotti et al., 2007). Cronbach's coefficient alpha was deployed in examining items' internal consistency. As noted by Churchill and Brown (2004), an instrument is termed as consistent if the items turn out to be highly correlated with one another; hence they can measure similar variables. Precisely, Nunnally and Bernstein (1994) state that if the Cronbach's alpha value is 0.60 or higher, then it is deemed adequate. In the current study, the lowest acceptable reliability level of alpha was 0.60 or higher based on Nunnally and Bernstein (1994) criterion. After entering all data into a computer, the SPSS 25.0 reliability program was done separately for each research item. Table 1 displays Cronbach's alpha values for different research factors. The table illustrates that the reliability coefficients were between 0.843 and 0.909 , implying that some scales were more reliable than others. As a result, the instruments designed in this research that involved service quality, customer orientation, and customer loyalty aspects were deemed reliable. Questionnaire validity pertains to whether or not it accurately measures the phenomenon being explored in the particular study. Accordingly, factor analysis (FA) was run on all the research items, precisely 29 items with Principal Component Analysis (PCA) used as the extraction approach and Varimax 
with Kaiser normalisation employed as rotation method. The logic of deploying FA is to reduce the data into smaller measurement units (Field, 2009). FA also helps in finding representative items from all variables or in some cases it facilitates the creation of new groups of variables lower in number or replacing the original variables (Hair et al., 2003). From Hair et al. (1998) understanding, if the loadings exceed or are equal to 0.50 , then the correlation is considered substantial. The PCA method was used in the current study, and the factor loading value of 0.50 was set as the standard cut-off point. Specific outcomes are shown in Table 1. The table illustrates that all the items had factor loadings higher than 0.50 on all factors apart from item 12 in the quality of service scale. Consequently, item 12 on this scale was deleted. Therefore, the scale comprised of 12 measurement items. Moreover, the latent root criterion or eigenvalue is deemed the most frequently adopted method for judging whether or not items are loading on a single factor (Hair et al., 2003). In the case of PCA, the factors having eigenvalues higher than 1 are judged significant. In the current research, all factors that had eigenvalues less than 1 were deemed inconsequential hence disregarded. Factor analysis showed that all items on each scale in this study formed one factor based on the principle that the eigenvalues should exceed 1. Consequently, it can be concluded that the measures deployed in this study are reliable and valid for use.

Table 1

Internal Consistency and Factor Loading Tests for CO, SQ \&CL

\begin{tabular}{|c|c|c|c|c|}
\hline Factor & Factor Loading & Eigenvalue & $\%$ Variance & Cronbach's Alpha \\
\hline \multicolumn{2}{|c|}{ CO Factor } & \multirow{13}{*}{6.65} & \multirow{13}{*}{67.652} & \multirow{13}{*}{0.871} \\
\hline $\mathrm{CO} 1$ & 0.702 & & & \\
\hline $\mathrm{CO} 2$ & 0.787 & & & \\
\hline $\mathrm{CO} 3$ & 0.856 & & & \\
\hline $\mathrm{CO} 4$ & 0.872 & & & \\
\hline $\mathrm{CO} 5$ & 0.708 & & & \\
\hline $\mathrm{CO} 6$ & 0.773 & & & \\
\hline $\mathrm{CO} 7$ & 0.719 & & & \\
\hline $\mathrm{CO} 8$ & 0.803 & & & \\
\hline $\mathrm{CO} 9$ & 0.887 & & & \\
\hline $\mathrm{CO} 10$ & 0.841 & & & \\
\hline CO11 & 0.771 & & & \\
\hline $\mathrm{CO} 12$ & 0.707 & & & \\
\hline \multicolumn{2}{|c|}{ SQ Factor } & \multirow{14}{*}{7.483} & \multirow{14}{*}{76.835} & \multirow{14}{*}{0.909} \\
\hline SQ1 & 0.673 & & & \\
\hline SQ2 & 0.632 & & & \\
\hline SQ3 & 0.766 & & & \\
\hline SQ4 & 0.751 & & & \\
\hline SQ5 & 0.708 & & & \\
\hline SQ6 & 0.768 & & & \\
\hline SQ7 & 0.614 & & & \\
\hline SQ8 & 0.837 & & & \\
\hline SQ9 & 0.747 & & & \\
\hline SQ10 & 0.752 & & & \\
\hline SQ11 & 0.625 & & & \\
\hline SQ12 & 0.441 & & & \\
\hline SQ13 & 0.589 & & & \\
\hline \multicolumn{2}{|c|}{ CL Factor } & \multirow{5}{*}{3.667} & \multirow{5}{*}{73.346} & \multirow{5}{*}{0.843} \\
\hline CL1 & 0.837 & & & \\
\hline CL2 & 0.797 & & & \\
\hline CL3 & 0.658 & & & \\
\hline CL4 & 0.804 & & & \\
\hline
\end{tabular}

\subsection{Analysis of Structural Model}

A SEM 9.30 (LISREL) was used to test the theoretical model hypothesised in this study. A LISREL model can be estimated in two ways. First, all measurement model paths, as well as structural models, are assessed concurrently. Alternatively, the paths of the two models can be appraised separately, an approach also known as two-stage analysis. Indeed, most researchers prefer a two-stage structural equation modelling process (Hair et al., 2003). However, in this study, a total of 205 observations were done for employees. Remarkably, such observations were not adequate for appraising the structural and measurement models at once. In this regard, the two-stage analysis method was chosen for estimation. Moreover, the paths linking latent variables and their particular indicators are known as the measurement model, while the paths that connect the latent variables are referred to as the structural model. To appraise fitness of the structural and measurement model, some fit indices were employed including the goodness-of-fit index (GFI), chi-square statistic, the adjusted GFI index (AGFI), the standardised root mean square residual (RMSR), as well as the normed fit index (NFI). Following the examination of the fit indices, all the parameter estimates together with their related significance levels using $t$ values or standard error were noted for the suggested structural model. Nonetheless, the parameter estimations for the measurement model were done in the previous part using the PCA method (as shown in Table 1). The general chi-square for the measurement model was 106.130 with $69.0 \mathrm{df}$ and a value of $p$ less than 0.00590 . In the case the chi-square is insignificant or $p$-value greater than $0.050(p>0.05)$, the model fit is 
considered appropriate. In other words, there is no remarkable difference between the real matrix and the predicted one (Loehlin, 1992). Notably, a small value of $\mathrm{p}$ of the model demonstrated a remarkable difference between the estimated and the actual matrix. The chi-square statistic tends to be sensitive to the number of parameters being estimated and sample size. As such, the normed chi-square ( $\chi 2 / \mathrm{df})$ is appropriate (Hair et al., 1998). In this study, the value of the normed chi-square was 1.490 for the measurement model. This lies within the commended levels of between 1.00 and 2.00, implying that the model fit is appropriate (Hair et al., 1998). Besides the normed chi-square, other fit indices used including GFI = 0.92, AGFI =0.87, and NFI $=0.89$ fell around the anticipated level of 0.900 , indicating that the model represented the observed data (Hair et al., 1998). Finally, the standardised RMSR (0.0530) implied that the degree of the variances between the projected and actual covariance matrices is comparatively small (Brown \& Chdeck, 1993). The general structural model chi-square was 107.620 with $70.0 d f$ and $\mathrm{p}<0.0057$. Table 2 demonstrates the insignificant difference between the measurement model and the structural model (chi-square difference of $1.49, d f=1$ ). Given that the measurement model enables all latent constructs to cover a comparison of the conceptual and the measurement model is an indication that the model is fit. However, a lack of considerable difference between the models meant that the data obtained approved the theory. Other structural model fit values were nearly identical to the ones for the measurement model; $\chi 2 / \mathrm{df}=1.480$; GFI $=0.92$, AGFI $=0.870, \mathrm{NFI}=0.890$, and standardized RMSR0.0510 thereby satisfying the standard fit criteria noted earlier (see table 2).

Table 2

Goodness-of-Fit Indices for Measurement and Structural Models

\begin{tabular}{llllllll}
\hline Model & $\boldsymbol{\chi 2}$ & $\boldsymbol{d} \boldsymbol{f}$ & $\boldsymbol{\chi} \mathbf{2} \boldsymbol{d} \boldsymbol{f}$ & GFI & AGFI & NFI & RMSR \\
\hline MM & 106.13 & 69 & 1.49 & .92 & .87 & .89 & .053 \\
SM & 107.62 & 70 & 1.48 & .92 & .87 & .89 & .051 \\
\hline
\end{tabular}

MM: Measurement Model; SM: Structural Model; GFI: Goodness-of Fit Index; AGFI: Adjusted Goodness-of Fit Index; NFI: Normed Fit Index; RMSR: Standardized Root Mean Square Residual.

In the structural model, LISREL offers probable coefficients, standard errors, as well as calculated values of $t$ for all coefficients. In this research, the degree of the parameter approximations for the structural model was measured using $t$ values. A hypothesis is affirmed if the projected path coefficient is substantial and bears the hypothesised sign. In the current research, one-tailed significance levels were deployed because the hypotheses formulate precise predictions of the direction of the influence of one variable on the other. Value of $t$ greater than 1.2820 corresponds to the value of p greater than 0.10 , indicating insignificance, a $t$-value greater than 1.6450 corresponds to value of $\mathrm{p}$ less than 0.050 implying moderate significance. In contrast, the value of $t$ greater than 2.3260 corresponds to the value of $\mathrm{p}$ less than 0.010 indicating strong significance (Harnett $\&$ Murphy, 1985). Table 3 illustrates the path coefficients for the structural portion of the suggested model.

Table 3

Structural Standardized Path Coefficients for Proposed Model

\begin{tabular}{|c|c|c|c|c|c|}
\hline Model Relations & Std. Path Coefficient & $T$ Value & Mediation Path & Indirect Effect & $T$ Value \\
\hline $\mathrm{CO} \rightarrow \mathrm{CL}(\gamma 11)$ & .09 & 1.08 & $\mathrm{CO} \rightarrow \mathrm{SQ} \rightarrow \mathrm{CL}$ & -.02 & -0.019 \\
\hline $\mathrm{CO} \rightarrow \mathrm{SQ}(\gamma 21)$ & .28 & $2.24 *$ & $\mathrm{CO} \rightarrow \mathrm{CS} \rightarrow \mathrm{CL}$ & .59 & $0.405 * *$ \\
\hline $\mathrm{CO} \rightarrow \mathrm{CS}(\gamma 31)$ & .74 & $5.98 * *$ & \multirow{3}{*}{\multicolumn{3}{|c|}{$\frac{\text { Model Fit }}{\chi^{2}=107.62}, d f=70, \chi 2 / d f=1.48, \mathrm{GFI}=.92, \mathrm{AGFI}=.87, \mathrm{NFI}=.89, \mathrm{RMSR}=.051$}} \\
\hline $\mathrm{SQ} \rightarrow \mathrm{CL}(\beta 21)$ & -.07 & -0.09 & & & \\
\hline $\mathrm{CS} \rightarrow \mathrm{CL}(\beta 31)$ & .81 & $6.79 * *$ & & & \\
\hline
\end{tabular}

Note: CO: Customer Orientation; SQ: Service Quality; CL: Customer Loyalty; GFI: Goodness-of Fit Index; AGFI: Adjusted Goodness-of Fit Index; NFI: Normed Fit Index; RMSR: Standardized Root Mean Square Residual.

In Table 3, the standardised path coefficient between customer orientation (CO) and customer loyalty (CL) did not support the first hypothesis $H 1(\gamma 11=0.09, \mathrm{t}=1.080, \mathrm{p}>0.10)$. However, the second hypothesis $H 2$ about the causal correlation between $\mathrm{CO}$ and service quality (SQ) was supported $(\gamma 21=0.28, \mathrm{t}=2.240, \mathrm{p}<0.05)$. The third hypothesis $H 3$ predicting positive and significant correlation between CO and customer satisfaction (CS) was firmly supported $(\gamma 31=0.74, \mathrm{t}=5.980$, $\mathrm{p}<0.01)$. Besides, the standardised path coefficient between SQ and CL did not support the $4^{\text {th }}$ hypothesis $H 4(\beta 21=-0.07, \mathrm{t}$ $=-0.090, \mathrm{p}>0.10)$ but the $5^{\text {th }}$ hypothesis $H 5$ about the causal association between CS and CL was strongly supported $(\beta 31=$ $0.81, \mathrm{t}=6.790, \mathrm{p}<0.01)$. Additionally, the findings illustrated that the $6^{\text {th }}$ hypothesis $(H 6)$ about the mediating role of SQ between $\mathrm{CO}$ and $\mathrm{CL}$ was not approved, CO indicated an insignificant indirect impact on CL through SQ $(\gamma 21 \times \beta 21=-0.02, \mathrm{t}$ $=-0.0190, \mathrm{p}>0.10)$. The $7^{\text {th }}$ hypothesis $(H 7)$ about the mediating role of CS between CO and CL was firmly supported as CO demonstrated a significant indirect influence on CL through CS $(\gamma 31 \times \beta 31=0.59, \mathrm{t}=0.4050, \mathrm{p}<0.01)$ (see Figure 2). In this regard, CS fully mediates the relationship between CO and CL. This study was based on the desire to comprehend the relationship between frontline employees' customer orientation and customers' decision to remain loyal to a particular organization, focusing on the quality of service and customer satisfaction to explain this association. The outcomes illustrate that frontline worker customer orientation was significantly linked to customer experience, mainly, quality of service and customer satisfaction. Additionally, the findings indicated that contact employee customer orientation was strongly associated with customer satisfaction, which then positively influences customer loyalty. That is, the link between customer loyalty and customer orientation was determined by the extent to which the customers are satisfied with services offered by the clinics. 


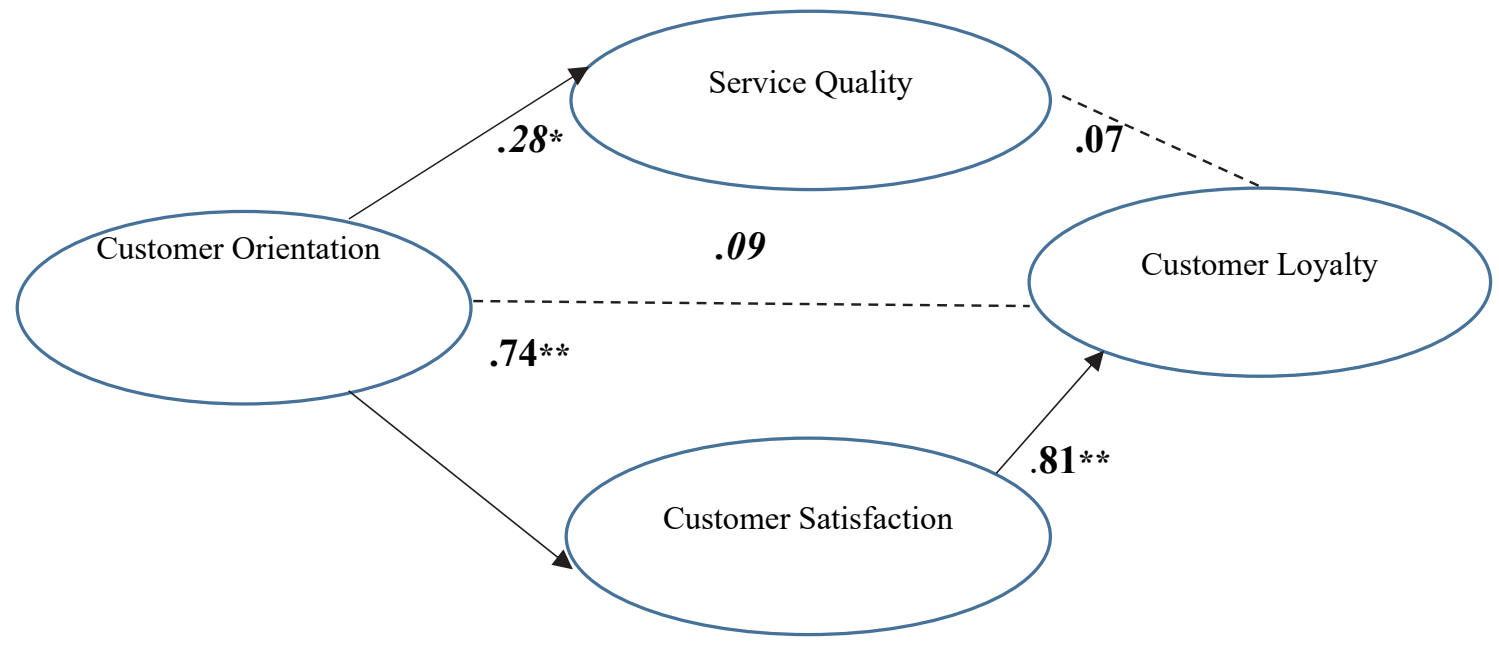

$* p<.05 . * * p<.01 ;$ Hypothesis were confirmed $(\longrightarrow)$; Hypothesis was not confirmed $(------)$.

Fig. 2. Customer Orientation-Customer Loyalty Model via Service Quality and Customer Satisfaction

\section{Discussion and Conclusion}

The findings of this research support the predominant theory or belief that organisations that are customer-oriented benefit immensely. Specifically, the results have shown that contact employees mainly registration staff and receptionists with the level of customer orientation positively influence patients' view of clinics' quality of service and eventually result in consumer loyalty and satisfaction. The study outcome sends an important message to healthcare centres on the essence of having customer-oriented employees. This study employed the customer orientation approach as a function of inborn characteristics and situational factors. Based on this approach, healthcare managers need to establish a proper profile of personality traits and hire individuals who fit particular profile. Notably, although organisations spend much effort to choose applicants with appropriate personality traits, they might find that those hired have different customer focus levels. Such a situation shows the importance of the other variables in the service orientation equation, including environmental or situational factors. Practical, situational, environmental, or situational factors might encompass providing the employee with relevant training and rewarding exemplary performance based on customer feedback to boost worker customer orientation. For instance, Kim et al. (2009) acknowledged the essence of training and rewarding employees, particularly in-service industries. Despite that, the outcome of this research did not affirm the presumptions of a positive direct association between customer loyalty and customer orientation, some studies in the literature review established that customer orientation is a key driver of customer loyalty (Dadia \& Idenedo, 2017; Mohammad et al., 2013; Ruud et al., 2016). Such a relationship might occur because services are intangible and characterised by interactivity and inseparability. In this regard, consumers will consume and assess service process output in-service employee presence (Teng \& Barrows, 2009). Another remarkable matter addressed in this research is the correlations among CO, SQ, and CS. The standardised path coefficient between CO and SQ variables was 0.280 , implying that the correlation is substantial. In other words, employee $\mathrm{CO}$ has a positive influence on consumers' perceived quality of service. The findings align with the outcomes of Venus and Safaeeian (2014), Jayavardna and Farrell (2011), and Ming et al. (2013) studies which indicated that $\mathrm{CO}$ is positively related to customer perceived quality of service. Essentially, employee-customer interaction becomes fundamental for determining the customer's perception of SQ. Accordingly, Gazzoli et al. (2013) underlined workers' attitudes such as their preparedness to serve, behaviour such as helpfulness, and expertise such as knowledge in service being delivered as three fundamental factors that determine customer view of SQ. Moreover, the literature underscores that personal interactions between customers and employees have a significant influence on customer views of service quality (Kim, 2011; Gazzoli et al., 2013; Jarideh, 2016). Similarly, Ekinci and Dawes (2009) conceptually noted that CO is an essential predictor of SQ and empirically showed CO mediates the correlation between worker personality and CS. Primarily, SQ in a company depends totally on frontline employees' ability to interact graciously with clients in all situations, thus offering excellent CS (Blocker et al., 2011). As a result, customers will have a positive view based on the quality of interaction during service encounters, resulting in higher levels of satisfaction.

The findings of this study also illustrated that there is a significant link between CO and CS. As such, the CO of workers has a positive effect on CS. The outcomes are in line with the findings Venus and Safaeeian (2014) study, which indicated that from the customer view, service delivery speed is an important determiner of CS. Ming et al., (2013) and Jayavardna and Farrell (2011) also pointed out that CO, the perceived value on contentment, behavioural intentions have a positive impact on customers in service sectors. Besides, research has pointed to a possible direct association between CS and the frontline employee's service orientation (Jarideh, 2016; Raie et al., 2014;). Other researchers also reported similar outcomes that CS depends directly on certain particular contact employees' behaviours (Lee et al., 2011; Lee et al., 2013; Liang \& Zhang, 2012). 
Another major issue addressed in the current research is the association between SQ, CS, and CL. The outcomes ascertained that decisions of customers to remain loyal are directly determined by their contentment rather than the quality of service. Thus, $H 4$ is rejected, and H5 is supported. Remarkably, Kim's (2011) study showed that CS has a more substantive influence on CL than SQ. The outcomes are in line with the findings of Mohsan et al. (2011), Chiguvi and Guruwo (2017), and Waari (2018) studies. In expounding this, some researchers showed that consumers' view of service quality has an indirect impact on CL via CS. For instance, Kim et al. (2013) clarified the association between SQ and CS best. They underlined that quality is one of the prospective service dimensions that are considered to boost CS. Similarly, a study by Rust and Oliver (1994) portrayed that contentment results from various sources and a higher satisfaction level with particular sources might offset the impacts of lower satisfaction levels with others. Such arguments essentially justify the finding of this study that SQ as a key determiner of customer satisfaction as opposed to customer loyalty and supports the mediating influence of customer satisfaction between perceived quality of service and consumer loyalty. In essence, such sentiments further affirm the rejection of $H 6$ in the current study.

In this study, the $6^{\text {th }}$ hypothesis about the arbitrating role of SQ between employee consumer orientation and loyalty of customers was not ascertained. Worker consumer orientation indicated a negligible indirect impact on customer loyalty through the quality of service. Several studies concluded that loyalty of customers results from the satisfaction of consumers as opposed to the quality of service as underlined by Kim et al. (2011). Besides, the considerable indirect path from employee customer orientation to the loyalty of customers in this research $(H 7)$ implied that worker customer satisfaction plays a key part as a full rather than a partial as a mediator between worker customer orientation and the decision by customers to remain loyal to a particular organisation. Similar to the $4^{\text {th }}$ hypothesis (H4), no remarkable path from the quality of service to the loyalty of customers might support the likelihood of consumer satisfaction as a complete mediator between customer perceived quality of service and reliability of customers. In other words, the high extent of consumer orientation among frontline workers was shown through their service performance. In turn, this led to significant levels of satisfaction of customers, which then influenced consumers' decision to be loyal to the organisation. Accordingly, the clinics that can attain and sustain customer satisfaction are guaranteed to repeat business from the consumers.

Given the positive influence of employee-customer orientation on the experience of customers, the following recommendations are made. Firstly, organisations should ensure employee training from time to time on courses related to customer satisfaction to increase their skills, information, knowledge, expertise, as well as technical competence at work. After hiring, organisations should train their staff on professional qualifications and kind of behaviour desired at work when interacting with customers. Notably, the training should involve the entire work duration to enable employees to positively respond to technology changes, the customer as well as job requirements. The current research adds to the existing literature by its exceptional study design. Most previous researches that point to a positive link between contact workers' consumer orientation and consumer outcome variables, such as satisfaction, often collected the ratings of the research variables from consumers (Dean, 2007; Jarideh, 2016). Nonetheless, this research employed two sources of data, namely, consumer-oriented conducts, as reported by contact of frontline workers themselves as well as clinics' patients who offered their views of the quality of service, satisfaction, as well as loyalty to the service firm. This study design minimised the influence of common method variance or single source and hence the outcomes present the valid, reliable, and true impact of employee-customer orientation (predictor) on consumer views of a service organisation as the outcomes. Moreover, the present research has essential applied implications for managers of healthcare clinics. From a human resources management view, this research outlines the significance of employee attraction, development, and retention who show a consumer-focused personality. Therefore, the best approaches in the selection and hiring of employees should be executed to ensure that service contact workers meet the characteristics of the ideal consumer-oriented profile.

The study has some limitations, including that it was limited to only presenting an analysis of the association in a crosssectional timeline. The dynamic business environment should be identified. In this regard, future studies must employ longitudinal design flow up to further ascertain whether or not the correlation between the variables considered in the present study will have changed. In addition to time and cost-related limitations, the data employed in this study was gathered only from the governmental sector, thereby reflecting an exceptional service culture. Further, given that the data was obtained from only one service sector, the generalisation of the outcomes to other service industries might be questionable. Additionally, despite that training was offered to managers and employees in clinics on ways of gathering the data and thus minimise possible bias, the researcher still relied on the managers to gather data from workers and the workers to collect further data from the customers. Besides, the suggested model in this research is rather simple since it examines the influence of customer orientation entirely on the loyalty of customers via the arbitrating role of the consumer experience. Therefore, future studies on this topic should build more sophisticated consumer orientation models. For instance, it will be interesting to understand how the quality of service influences consumer satisfaction because examining other mediating instruments could assist in explaining and supporting why consumer orientation does not have an indirect influence on the loyalty of customers through the quality of service. 


\section{References}

Abdolahian, S., \& Foroozandeh, K. (2011). Customer orientation and its importance for organizations. Transport and Development, 50(1), 60-72.

Aburayya, A., Alawadhi, D., \& Taryam, M. (20019a). A conceptual framework for implementing TQM in the primary healthcare centers and examining its impact on patient satisfaction. International Journal of Advanced Research, 7(3), 1047-1065.

Aburayya, A., Alshurideh, M., Albqaeen, A., Alawadhi, D., \& Ayadeh, I. (2019b). An investigation of factors affecting patients waiting time in primary health care centers: An assessment study in Dubai. Management Science Letters, 10(6), 1265-1276.

Aghamolaei, T., Eftekhaari, T.E., Rafati, S., Kahnouji, K., Ahangari, S., Shahrzad, M.E., Kahnouji, A., \& Hoseini, S.H. (2014). Service quality assessment of a referral hospital in Southern Iran with SERVQUAL technique: patients' perspective. BMC Health Services Research, 14(1), 25-322

Al Bolushi, M., Olorogun, L.A., Boubacar, I., \& Houjeir, R. (2017). Empirical study of quality healthcare services: Public and private healthcare in the United Arab Emirates. International Journal of Applied Business and Economic Research, 15(19), 169-180.

Alghamdi, F. (2018). Total quality management and organizational performance: A possible role of organizational culture. International Journal of Business Administration, 9(4), 186-200.

Baloglu, S. (2002). Dimensions of customer loyalty. Cornell Hotel and Restaurant Administration Quarterly, 43(1), 47-59.

Blocker, C.P., Flint, D.J., Myers, M.B., \& Slater, S.F. (2011). Proactive customer orientation and its role in creating customer value in global markets. Journal of the Academy of Marketing Science, 39(2), 216-233.

Brockman, B.K., Jones, M.A., \& Becherer, R.C. (2012). Customer orientation and performance in small firms: Examining the moderating influence of risk-taking, innovativeness, and opportunity focus. Journal of Small Business Management, 50(3), 429-446.

Brown, M. W., \& Chdeck, R. (1993). Alternative ways of assessing model fit. In K. A. Bollen \& J. S. Long, Testing structural equation models (pp.136-162). Sage.

Brown, S.P., \& Lam, S.K. (2008). A meta-analysis of relationships linking employee satisfaction to customer responses. Journal of Retailing, 84(3), 243-255.

Brown, T.J., Mowen, J.C., Donavan, D.T., \& Licata, J.W. (2002). The customer orientation of service workers: Personality trait effects on self- and supervisor performance ratings. Journal of Marketing Research, 39(1), 110-119.

Carman, J. M., Shortell, S. M., Foster, R. W., Hughes, E. F., Boerstler, H., \& O’Brien, J. L. (1996). Key for successful implementation of total quality management in hospitals. Health Care Management Review, 21(1), 48-60.

Chen, K., Ouyang, Y., Huang, Y., \& Lee, T. (2016). The study on the service quality and satisfaction of public hot springs hotels. The International Journal of Organization Innovation, 9(1), 187-199.

Chiguvi, G., \& Guruwo, P. (2017). Impact of customer satisfaction on customer loyalty in the banking sector. International Journal of Scientific Engineering and Research, 5(2), 55-63.

Churchill, G.A., \& Brown, T.J. (2004). Basic marketing research. 5th ed. South-Western College Pub.

Dean, A.M. (2007). The impact of customer orientation of call center employees on customers' affective commitment and loyalty. Journal of Service Research, 10(2), 161-173.

Ekinci, Y., \& Dawes, P.L. (2009). Consumer perceptions of frontline service employee personality traits, interaction quality, and consumer satisfaction. The Service Industries Journal, 29(4), 503-521.

Farrell, M.A., \& Oczkowski, E. (2012). Organizational identification and leader-member exchange influences on customer orientation and organizational citizenship behaviors. Journal of Strategic Marketing, 20(4), 365-377.

Fatima, T., Malik, S.A., \& Shabbir, A. (2018). Hospital healthcare service quality, patient satisfaction, and loyalty: An investigation in the context of private healthcare systems. International Journal of Quality \& Reliability Management, 35(6), $1195-1214$.

Field, A. (2009). Discovering statistics using SPSS. 3rd ed. London: Sage Publications Limited.

Gazzol, G., Hancer, M., \& Kim, B. (2013). Explaining why employee-customer orientation influences customers' perceptions of the service encounter. Journal of Service Management, 24(4), 382-400.

Hair, F.J., Anderson, R. E., Tatham, R. L., \& Black, W. C. (1998). Multivariate data analysis. 5th ed. Prentice-Hall International.

Hair, J., Babin, B., Money, P., \& Samouel, P. (2003). Essentials of business research methods. Wiley.

Hennig-Thurau, T. (2004). Customer orientation of service employees: Its impact on customer satisfaction, commitment, and retention. International Journal of Service Industry Management, 15(5), 460-478.

Jarideh, N. (2016). The investigation of effect of customer orientation and staff service-oriented on Qquality of service, customer satisfaction and loyalty in hyper star stores. International Journal of Science and Research, 5(3), $1837-1841$.

Kheng, L.L., Mohamad, O., Ramayah, T., \& Mosoahab, R. (2010). The impact of service quality on customer loyalty: A study of banks in Penang, Malaysia. International Journal of Marketing Studies, 2(2), 57-66.

Kim, H. J., McCahon, C., \& Miller, J. (2003). Service orientation for contact employees in Korean casual-dining restaurants. International Journal of Hospitality Management, 22(1), 67-83.

Kim, H. J., Shin, K., \& Swanger, N. (2009). Burnout and engagement: A comparative analysis using the big five personality dimensions. International Journal of Hospitality Management, 28(1), 96-104. 
Kim, H.J. (2011). Service orientation, service quality, customer satisfaction, and customer loyalty: Testing a structural model. Journal of Hospitality Marketing \& Management, 20(1), 619-637.

Lee, C.K., Song, H.J., Lee, H.M., Lee, S., \& Bernhard, B.J. (2013). The impact of CSR on casino employees' organizational trust, job satisfaction, and customer orientation: An empirical examination of responsible gambling strategies. International Journal of Hospitality Management, 33(9), 406-415.

Lee, Y.K., Kim, Y.S., Son, M.H., \& Lee, D.J. (2011). Do emotions play a mediating role in the relationship between owner leadership styles and manager customer orientation, and performance in a service environment?. International Journal of Hospitality Management, 30(4), 942-952.

Liang, R.D., \& Zhang, J.S. (2012). The effect of service interaction orientation on customer satisfaction and behavioral intention: The moderating effect of dining frequency. Asia Pacific Journal of Marketing and Logistics, 24(6),153-170.

Loehlin, J. C. (1992). Latent variable models: An introduction to factor, path, and structural analysis. 2nd ed. Lawrence Erlbaum.

Ming, I.E., Xu, A., \& Tan, Z. (2013). Exploring the impact of brand image on customer loyalty and commitment in China. Journal of Technology Management in China, 4(8), 132-144.

Mohammad, A., Bin Rahid, B., \& Bin Tahir, S. (2013). Assessing the influence of customer relationship management (CRM) dimensions on organization performance: An empirical study in the hotel industry. Journal of Hospitality and Tourism Technology, 4(3), 228-247.

Mohsan, F., Nawaz, M., Khan, M., Shaukat, Z., \& Aslam, N. (2011). Impact of customer satisfaction on customer loyalty and intentions to switch: Evidence from the banking sector of Pakistan. International Journal of Business and Social Science, 2(16), 263-270.

Morgan, M.D. (1979). The dynamics of an introduced population of Mysis relicta in Emerald bay and lake Tahoe. University of California.

Nunnally, J. C., \& Bernstein, I. H. (1994). Psychometric theory. McGraw- Hill.

Oliver, R.L. (1981). Measurement and evaluation of satisfaction processes in retail settings. Journal of Retailing, 57(3), 2548.

Parasuraman, A., Zeithaml, V.A., \& Berry, L.L. (1985). A conceptual model of service quality and implications for future research. Journal of Marketing, 49(1), 41-50.

Parasuraman, A., Zeithaml, V.A., \& Berry, L.L. (1988). SERVQUAL: A multiple-item scale for measuring consumer perceptions of service quality. Journal Retail, 64(1), 12-40.

Pathirana, U.P.G.Y. (2019). Impact of SERVQUAL model dimensions for customer satisfaction. International Journal of Academic Research in Business and Social Sciences, 9(1), 1075-1085.

Rai, A., \& Medha, S. (2013). The antecedents of customer loyalty: An empirical investigation in life insurance context. Journal of Competitiveness, 1(2), 139-163.

Raie, M., Khadivi, A., \& Khadaie, R. (2014). The effect of employees' customer orientation, customer's satisfaction and commitment on customer's sustainability. Arabian Journal of Business and Management Review, 4(1), 109-121.

Rust, R. T., \& Oliver, R. L. (1994). Service quality: New directions in theory and practice. Sage.

Ruud, T. F., Peer, C.F., \& Paul T.M. (2016). How important is customer orientation for firm performance? A fuzzy set analysis of orientations, strategies, and environments. Journal of Business Research, 69(16), 1428-1436.

Scotti, D. J., Harmon, J., \& Behson, S.J. (2007). Links among high-performance work environment, service quality, and customer satisfaction: an extension to the healthcare sector. Journal of Healthcare Management, 52(2), 109-124.

Teng, C.C., \& Barrows, C.W. (2009). Service orientation: Antecedents, outcomes, and implications for hospitality research and practice. The Service Industries Journal, 29(10), 1413-1435.

U.S.-U.A.E. Business Council. (2018). The UAE's Growth Manufacturing Sector. [pdf] http://www.usuaebusiness.org/wpcontent/uploads/2018/01/Manufacturing-Report.pdf

UAE Ministry of Economy. (2019). Annual Economic Report 201-26th Edition. [pdf] https://www.economy.gov.ae/EconomicalReportsEn/Annual\%20Economic\%20Report\%202018.pdf

Venus, D., \& Safaeeian, M. (2014). Applied methods of marketing banking services to Iranian banks. Look at knowledge.

Waari, D.N. (2018). The effect of customer satisfaction on customer loyalty: The moderation roles of experiential encounter and customer patronage. Journal of Business and Management, 20(4), 74-80.

Yazdani, H., Zare, A., Nasiri, M., \& Asdnzhad, M. (2011). Examine the relationship between customer orientation and organizational citizenship behavior. Landscape Business Management, 6(1), 53-69.

Zablah, A.R., Franke, G.R., Brown, T.J., \& Bartholomew, D.E. (2012). How and when does customer orientation influence frontline employee job outcomes? A meta-analytic evaluation. Journal of Marketing, 76(3), 21-40.

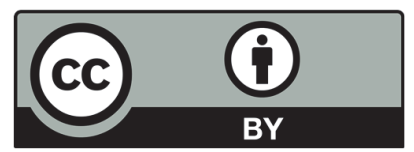

(C) 2020 by the authors; licensee Growing Science, Canada. This is an open access article distributed under the terms and conditions of the Creative Commons Attribution (CC-BY) license (http://creativecommons.org/licenses/by/4.0/). 